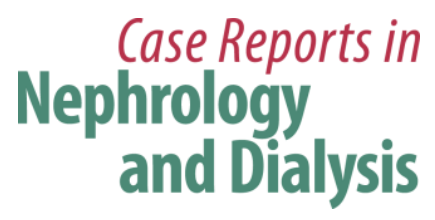

Case Rep Nephrol Dial 2018;8:121-129

DOI: $10.1159 / 000489923$

Published online: July 25, 2018

(C) 2018 The Author(s)

Published by S. Karger AG, Basel

www.karger.com/cnd

This article is licensed under the Creative Commons Attribution-NonCommercial 4.0 International License (CC BY-NC) (http://www.karger.com/Services/OpenAccessLicense). Usage and distribution for commercial purposes requires written permission.

\title{
Salvage of Hemodialysis Catheter in Staphylococcal Bacteremia: Case Series, Revisiting the Literature, and the Role of the Pharmacist
}

\author{
Wasim S. El Nekidya ${ }^{a}$ Derrick Soong ${ }^{b} \quad$ Albert Kadric $^{c}$ Osama Tabbara ${ }^{a}$ \\ Amina Ibrahim ${ }^{d}$ Islam M. Ghazi ${ }^{\mathrm{e}}$ \\ a Department of Pharmacy, Cleveland Clinic Abu Dhabi, Abu Dhabi, UAE; ${ }^{b}$ Department of \\ Pharmacy, Windsor Regional Hospital, Windsor, ON, Canada; 'Department of Nephrology,

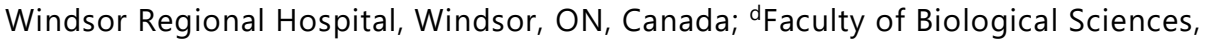 \\ University of Windsor, Windsor, ON, Canada; ePhiladelphia College of Pharmacy, \\ University of the Sciences, Philadelphia, PA, USA
}

\section{Keywords}

Hemodialysis - Staphylococcal bacteremia - Lock solutions · Catheter salvage - Role of the pharmacist

\begin{abstract}
Catheter-related blood stream infections comprise a major concern in hemodialysis patients, leading to increased mortality, morbidity, and cost of treatment. Prompt appropriate systemic antibiotics treatment, which includes administration of appropriate systemic antibiotics and, frequently, catheter removal and replacement, is warranted. However, in hemodialysis patients, repeated catheter insertions may cause central vein stenosis and thrombosis which limits the future availability of hemodialysis access. Lock solutions containing antibiotics and anticoagulants, instilled directly into the catheter lumen after each dialysis, have been successfully utilized for catheter salvage but higher rates of recurrence and complications were observed in
\end{abstract}




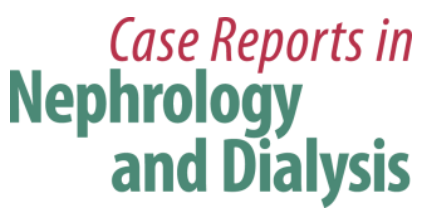

Case Rep Nephrol Dial 2018;8:121-129

DOI: 10.1159/000489923

(c) 2018 The Author(s). Published by S. Karger AG, Basel www.karger.com/cnd

El Nekidy et al.: Antibiotic Lock Solution in Hemodialysis Catheter Salvage

infections resulting from staphylococcal species. We report several cases of catheter salvage using antibiotic lock solution in staphylococcal bacteremia with the purpose of stimulating the interest in randomized clinical trials. Evaluating the risk and benefits of catheter salvage in this patient subset in light of optimized systemic antibiotic dosing, improved lock solution use, and multidisciplinary involvement, balanced with the critical need to prevent unnecessary vascular trauma, is of great importance.

(C) 2018 The Author(s)

Published by S. Karger AG, Basel

\section{Introduction}

Ample evidence indicates the gravity and substantial impact of catheter-related blood stream infections (CRBSI) on morbidity, mortality, and the cost of health care. Insertion of long-term central venous catheters (CVC) is essential for the care of patients receiving chemotherapy and hemodialysis [1]. Reportedly, 5 million CVCs are inserted annually in the US associated with an incidence of 400,000 related blood stream infections (BSI) [2]. The National Nosocomial Infections Surveillance (NNIS) revealed the incidence is up to 5.2 BSI per 1,000 catheter days [3].

Although arteriovenous graft and arteriovenous fistula (AVF) provide more favorable dialysis access in most hemodialysis patients, CVCs are still used in $40 \%$ of these patients for various reasons, such as waiting for vascular surgery, maturation of fistula, lack of operable vascular anatomy, patient preference, or short life expectancy [4,5]. Preserving venous access patency is crucial for those patients particularly in cases with limited remaining access sites. The drawback of traditional care for BSI in hemodialysis patients involving removal and replacement of CVC is the possibility of venous stenosis and thrombosis, which jeopardizes the availability of future dialysis access $[4,5]$.

Establishing an AVF is dependent on the peripheral veins' patency, sufficient size, and elasticity to allow for dilation and maturation of the fistula post-surgical construction. In addition, the AVF function requires a patent venous circuit. The frequent venipuncture and the excessive use of peripheral intravenous lines and peripherally inserted CVC (PICC) can damage the veins, impair venous circulation, and endanger future AVF construction. Smaller caliber CVCs (such as PICC and triple-lumen catheters) can also be associated with thrombus formation over a short term [6-8]. In addition, PICC lines are associated with central vein stenosis, thrombosis, and scarring of the peripheral veins $[9,10]$. Approximately $40 \%$ of patients with subclavian vein catheters and $20 \%$ with jugular vein catheters will develop central vein obstruction (venous stenosis or occlusion) secondary to previously inserted CVC. Irrespective of the location (subclavian or internal jugular), a larger number and longer duration of CVC use increases the risk of developing central vein stenosis. It was shown that it may take only between a few weeks to months following PICC insertion to render a vein useless for hemodialysis access $[9,10]$.

Anatomical sites that are conductive for creating arteriovenous graft or AVF are the cephalic and basilic veins in each arm) and these veins should be preserved [11]. As a result, many nephrology associations and agencies in North America have launched campaigns to save the veins of chronic kidney disease patients [12-14]. 


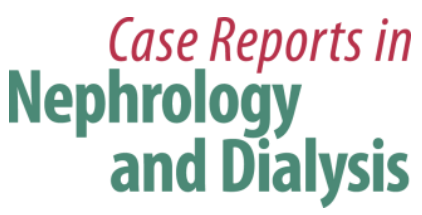

Case Rep Nephrol Dial 2018;8:121-129
\begin{tabular}{l|l} 
DOI: 10.1159/000489923 & $\begin{array}{l}\text { (c) 2018 The Author(s). Published by S. Karger AG, Basel } \\
\text { www.karger.com/cnd }\end{array}$ \\
\hline
\end{tabular}

Multiple pathogens are implicated in CRBSI including coagulase-negative Staphylococci, Staphylococcus aureus, Enterococci, Gram-negative bacilli, Pseudomonas aeruginosa, and Candida species. Several studies indicated the difficulty of treatment of staphylococcal infections without catheter removal and this is the recommended treatment strategy by the Infectious Diseases Society of America (IDSA) [15].

We are reporting eradication of CRBSI caused by Staphylococcus species in a series of 8 hemodialysis patients using antibiotic lock solution in conjunction with intravenous antibiotics to avoid the removal of catheter access. We documented all staphylococcal-related bacteremia cases after the implementation of catheter-related antibiotic lock policy at our institution in the following 18 months. In addition, we revisited the literature evaluating the plausibility of this approach.

\section{Case Series}

All of the cases presented here involved staphylococcal infections including coagulasenegative as well as methicillin-sensitive and -resistant species conveniently reviewed between 2013 and 2014 at a dialysis center affiliated with a community hospital serving several cities in Southwestern Ontario, Canada. To attempt catheter salvage, antibiotic lock solutions were locally instilled in the catheter space concomitantly with the appropriate intravenous antibiotics administration for the same duration. Patients were prescribed lock solution when the treating physician judged catheter salvage to be critical. The selection of systemic antibiotic and the composition of antibiotic lock solution (Table 1) were based on the culture and sensitivity results reported by the hospital's microbiology department. The lock solutions were prepared by aseptically reconstituting commercially available products and admixing with the desired anticoagulant, if applicable, in a sterile syringe for instillation into the catheter space at the end of each dialysis session where it dwelled until the next dialysis session (i.e., $44-68 \mathrm{~h}$ ).

\section{Case 1}

In a 47-year-old Caucasian male (weight $70 \mathrm{~kg}$, height $177 \mathrm{~cm}$ ), with a known history of hypertension, beta-lactam-documented allergy, and on hemodialysis for 3 years prior to this event, a dialysis catheter was inserted 30 months prior to the incident. Peripheral blood cultures as well as blood drawn from the catheter revealed methicillin-sensitive S. aureus (MSSA) bacteremia. To avoid possible allergic manifestations, the patient was treated with vancomycin $2,000 \mathrm{mg}$ i.v. $(28.5 \mathrm{mg} / \mathrm{kg}$ ) as a loading dose in the last $90 \mathrm{~min}$ of dialysis followed by 1,000 $\mathrm{mg}$ i.v. (14.2 $\mathrm{mg} / \mathrm{kg}$ ) after each subsequent dialysis (in the last 30-60 min of dialysis) plus combination vancomycin $(2.5 \mathrm{mg} / \mathrm{mL}) / 4 \%$ citrate antibiotic lock for 3 weeks. Vancomycin pre-hemodialysis concentrations were $>15 \mathrm{mg} / \mathrm{L}$ (target $15-20 \mathrm{mg} / \mathrm{L}$ ) during the 2 weeks of intravenous antibiotic therapy. The treatment was initiated while the patient was an outpatient. The patient experienced complete resolution of bacteremia confirmed by negative blood cultures. The catheter was removed 5 months after transplant surgery. 


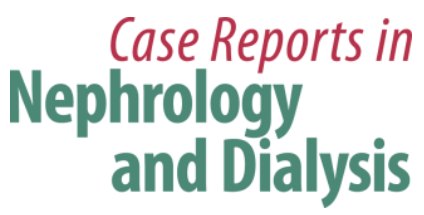

Case Rep Nephrol Dial 2018;8:121-129

DOI: $10.1159 / 000489923$

(C) 2018 The Author(s). Published by S. Karger AG, Basel www.karger.com/cnd

El Nekidy et al.: Antibiotic Lock Solution in Hemodialysis Catheter Salvage

Case 2

A 34-year-old white female (weight $46 \mathrm{~kg}$, height $166 \mathrm{~cm}$ ) with a medical history significant for type I diabetes, hypertension, ischemic heart disease, and on hemodialysis for 3 years prior to this encounter, grew coagulase-negative Staphylococcus from her CVC (oxacillin susceptible), where the catheter was changed on the same day of suspected blood stream infection. The patient was treated with parenteral cefazolin $2 \mathrm{~g}$ thrice weekly after each dialysis session in addition to cefazolin ( $5 \mathrm{mg} / \mathrm{mL}) /$ heparin $(5,000$ units $/ \mathrm{mL})$ lock solution for the duration of 1 week as deemed appropriate by the prescribing physician. The treatment was initiated and completed in the inpatient setting. Repeated cultures were all negative and the catheter remained in place with no recurrence in the 3-month follow-up period.

Case 3

A 37-year old African-Canadian male (weight $77 \mathrm{~kg}$, height $180 \mathrm{~cm}$ ), with a documented history of hypertension and type II diabetes, had been receiving hemodialysis for 4 months prior to this encounter. MSSA was recovered from blood samples withdrawn via CVC (which was inserted 2 months earlier) and peripheral veins. The treatment regimen consisted of cefazolin $2 \mathrm{~g}$ i.v. thrice weekly after dialysis plus cefazolin $(5 \mathrm{mg} / \mathrm{mL}) /$ heparin $(5,000$ units $/$ $\mathrm{mL}$ ) antibiotic lock instilled at the end of each dialysis for 2 weeks; the treatment started as inpatient and continued in the outpatient dialysis unit. All repeat cultures were negative and the permanent catheter was not removed for the follow-up period of 3 months.

Case 4

An 81-year-old quadriplegic African-Canadian female (weight $64 \mathrm{~kg}$, height $152.5 \mathrm{~cm}$ ), with a known history of hypertension, type II diabetes, and requiring hemodialysis 55 months prior to this encounter, was diagnosed with MSSA bacteremia, with blood samples collected from the CVC (which was inserted 21 months before the incidence of bacteremia) and peripheral veins. A prescription for cefazolin $2 \mathrm{~g}$ i.v. after each dialysis and cefazolin $(5 \mathrm{mg} / \mathrm{mL}) / \mathrm{hep}$ arin $(5,000$ units $/ \mathrm{mL})$ lock solution for 2 weeks were administered. Treatment was started in the outpatient dialysis unit. All repeat cultures were negative and the catheter was conserved intact. The patient expired 60 days later after admission; she was found unresponsive at a nursing home.

\section{Case 5}

A 36-year-old white male (weight $71 \mathrm{~kg}$, height $175 \mathrm{~cm}$ ) with hypertension, type I diabetes, heart disease, and on hemodialysis 51 months prior to this incident, developed MRSA bacteremia as shown by both CVC (which was inserted 1 week before the incidence of infection due to poor blood flow) and peripheral line blood cultures. The patient was treated with vancomycin $1,000 \mathrm{mg}$ i.v. $(14 \mathrm{mg} / \mathrm{kg})$ initially, then $1,500 \mathrm{mg}(21 \mathrm{mg} / \mathrm{kg})$ after the subsequent dialysis (due to low trough level) followed by $1,000 \mathrm{mg}$ i.v. after each subsequent dialysis with pre-hemodialysis concentrations $>15 \mathrm{mg} / \mathrm{L}$ (MRSA MIC was $0.5 \mathrm{mg} / \mathrm{mL}$ ). Treatment was initiated in the inpatient setting and was completed in the outpatient dialysis unit. The patient was also treated with vancomycin $(2.5 \mathrm{mg} / \mathrm{mL}) / 4 \%$ citrate lock solution for a 2 -week period. Microbiological eradication and resolution of symptoms were observed. The catheter was removed 1 month later after the patient had a successful kidney transplant. 


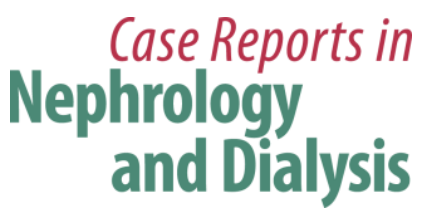

Case Rep Nephrol Dial 2018;8:121-129

DOI: $10.1159 / 000489923$

(c) 2018 The Author(s). Published by S. Karger AG, Base www.karger.com/cnd

El Nekidy et al.: Antibiotic Lock Solution in Hemodialysis Catheter Salvage

Case 6

A 67-year-old white female (weight $67 \mathrm{~kg}$, height $160 \mathrm{~cm}$ ) with a medical history significant for type II diabetes, hypertension, heart disease, and on hemodialysis for 23 months, developed MRSA bacteremia from the arterial line, CVC (which was inserted 4 months prior to this infection incident), and peripheral lines during her hospital admission and was started on

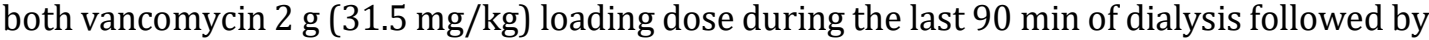
$1 \mathrm{~g}$ after each subsequent dialysis with a pre-hemodialysis level between 13 and $15 \mathrm{mg} / \mathrm{L}$ (MRSA MIC of $\leq 0.5 \mathrm{mg} / \mathrm{L})$. The patient also received vancomycin $(2.5 \mathrm{mg} / \mathrm{mL}) / 4 \%$ citrate lock solution. Due to catheter blockage by a blood clot irresponsive to dissolution by tissue plasminogen activator local treatment, the catheter was removed 6 months later due to loss of function. However, during the interim when the catheter was in use, there was no infection seen.

\section{Case 7}

An 82-year-old Asian female (weight $55 \mathrm{~kg}$, height $167 \mathrm{~cm}$ ), with a known history of hypertension, heart disease, and on hemodialysis 28 months prior to this incident, developed bacteremia with Acinetobacter baumanii and coagulase-negative Staphylococcus. The patient was treated with vancomycin loading dose of $1,500 \mathrm{mg}$ i.v. $(27.2 \mathrm{mg} / \mathrm{kg})$ during the last 60 min of dialysis followed by vancomycin $1,000 \mathrm{mg}$ maintenance dose after each subsequent dialysis, along with parenteral gentamicin $160 \mathrm{mg}(2.9 \mathrm{mg} / \mathrm{kg})$ loading dose and $60 \mathrm{mg}$ maintenance dose at the end of each dialysis, oral ciprofloxacin $500 \mathrm{mg}$ daily, plus gentamicin $5 \mathrm{mg} / \mathrm{mL}$ solution in normal saline lock. The three antibiotics and lock solution were started in the outpatient dialysis unit and were continued for 2 weeks without requiring hospital admission. The patient did not experience recurrent infection for a follow-up period of 1 year and continued dialysis through the same catheter.

\section{Case 8}

A 62-year-old white male (weight $125 \mathrm{~kg}$, height $167 \mathrm{~cm}$ ), with a known history of type II diabetes, heart disease, hypertension, stroke (paraplegic), and on hemodialysis 98 months prior to this infection incident, developed bacteremia secondary to coagulase-negative Staphylococcus from the CVC. The patient received vancomycin $2,000 \mathrm{mg}$ i.v. $(16 \mathrm{mg} / \mathrm{kg})$ for 2 consecutive dialysis sessions followed by vancomycin $1,000 \mathrm{mg}$ i.v. after each subsequent dialysis plus vancomycin $2.5 \mathrm{mg} / \mathrm{mL} / 4 \%$ citrate lock for 2 weeks total with complete cure, and the patient continued using the same catheter in the 6-month follow-up period.

\section{Discussion}

Staphylococcal bacteremia in patients with long-term CVCs carries the risk of hematogenous complications and recurrence which often necessitates catheter removal and replacement. In hemodialysis-dependent patients suffering from paucity of alternative hemodialysis access, catheter salvage is of upmost importance. In this case series, we have documented the utility of antibiotic lock solutions in salvaging the long-term dialysis catheter in patients with staphylococcal bacteremia in whom maintenance of patent dialysis access was critical. 


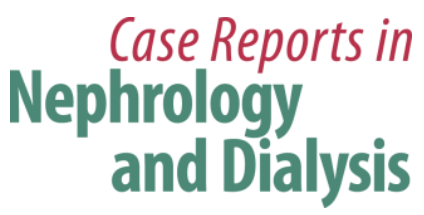

Case Rep Nephrol Dial 2018;8:121-129

DOI: $10.1159 / 000489923$

(C) 2018 The Author(s). Published by S. Karger AG, Basel www.karger.com/cnd

El Nekidy et al.: Antibiotic Lock Solution in Hemodialysis Catheter Salvage

Earlier studies examining the utility of antibiotic lock solutions in catheter salvage yielded varying results. Maya et al. [16] reported that of 113 hemodialysis patients with staphylococcal bacteremia, 35\% experienced persistent fever until the next dialysis session and in additional 24\% the infection recurred within 90 days. The pharmacokinetic/pharmacodynamic profile and target attainment was not discussed in the study; however, doses of antibiotics administered in the protocol were expected to achieve levels lower than the standard of practice today.

Ashby et al. [17] observed that in hemodialysis patients, attempted salvage was successful in $66.1 \%$ with no recurrence or complications, recurrent bacteremia was observed in $33 \%$ in the salvage group compared with $8.1 \%$ in the replacement group, but complications occurred in $0.9 \%$ in the former versus $14 \%$ in the latter group. Of note, $S$. aureus was the causative agent in $15.9 \%$ of cases, vancomycin dosing targeted trough of $5-10 \mathrm{mg} / \mathrm{L}$, and lock solutions contained only heparin. Krishnasami et al. [18] found 69\% of staphylococcal bacteremia to be eradicated successfully per protocol with a low incidence of $S$. aureus, the load dose of vancomycin was $20 \mathrm{mg} / \mathrm{kg}$ and the maintenance dose was $500 \mathrm{mg}$.

Based on the above studies and others, IDSA guidelines [15] that were published in 2009 recommended catheter removal for staphylococcal bacteremia; however, targeting higher vancomycin levels as the standard of practice, availability of diverse antibiotic lock solutions [19-22], and dire need of hemodialysis patients to minimize the frequency of catheter insertions should instigate clinical trials to re-examine the applicability of antibiotic lock solutions in maintaining the catheter in place and consequently conserving the options for dialysis access.

Central vein stenosis and thrombosis are well-described complications related to placement of short, long-term catheters. Endothelial damage occurs as a result of vein by an indwelling biologically incompatible foreign body. The injury is exaggerated further by constant movement of the catheter concomitant with respiration, movements of body parts, and changes in posture, as well as increased flow and turbulence from the arteriovenous access, alter the shear stress, resulting in platelet deposition and venous wall thickening. Trauma to the vessel wall results in thrombin generation, platelet activation, and expression of P-selectin with inflammatory response [23-25].

It is noteworthy to mention the role of nephrology-trained clinical pharmacists in providing effective therapy by selecting appropriate antibiotics which could be dosed after dialysis to conserve dialysis access. For example, the pharmacist recommended the use of cefazolin instead of cloxacillin/naficillin in MSSA and/or coagulase-negative Staphylococcus cases to mitigate the need of medication administration on non-dialysis days [26]. Selecting certain anti-infective agents promoted the early discharge from the hospital (i.e., patients did not have to remain in hospital for the full duration of antibiotic therapy), thereby reducing the overall cost of the patient's hospital admission. The pharmacist also served as liaison between infectious diseases and nephrology physicians, observed appropriate drug dosing and monitoring, and finally provided education to minimize vascular trauma to hemodialysis patients $[27,28]$. The majority of antibiotic lock solutions are labeled with a short stability period, so they need to be prepared just before instilling them into the patient's catheter (especially for the long inter-dialytic time). Ideally, antibiotic lock solutions are prepared at the beginning of the dialysis session in the pharmacy and transferred to the dialysis unit at the end of the session, this coordination of delivery of care is another role for the nephrology pharmacist. 


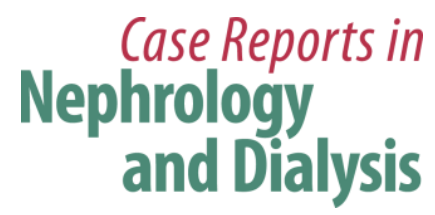

\begin{tabular}{l|l}
\hline Case Rep Nephrol Dial 2018;8:121-129 \\
\hline DOI: 10.1159/000489923 & $\begin{array}{l}\text { (c) } 2018 \text { The Author(s). Published by S. Karger AG, Basel } \\
\text { www.karger.com/cnd }\end{array}$
\end{tabular}

The observations in this report highlight the feasibility of successful microbiological eradication and clinical resolution of staphylococcal bacteremia in hemodialysis patients while maintaining the catheter in place to sustain the availability of dialysis access. The realization of the goals of infectious diseases [14, 29, 30] and renal groups [7] guidelines can be achieved through the selection of a treatment approach with a comprehensive view of the patient, maximizing the efficacy of systemic antibiotics, choice of the appropriate lock solution, and collaborative efforts of various health care disciplines. The successful treatment reported herein could be attributed to appropriate systemic therapy alone or in combination with antibiotic lock solutions; this remains to be a subject for a future study.

The cases presented in this report could provide insights for a randomized controlled clinical trial to investigate catheter salvage in this patient population where it is needed most. Nonetheless, several factors remain to be defined - for instance, the optimal antibiotic/anticoagulant concentrations of lock solution, when to start lock solution, the adequate dwell time, the required spectrum of antimicrobial coverage, patient characteristics predicting success or failure, and involvement of various health care professionals in decision-making to support clinical decisions that consider the risks of microbiological eradication failure and permanent loss of feasible dialysis access.

\section{Statement of Ethics}

The study conforms to all guidelines for human research and the protocol has been granted exempt status from Research Ethics Board in our institution. Due to the retrospective nature of data collection, the need for informed consent was waived.

\section{Disclosure Statement}

All the authors declare no conflict of interest.

\section{Funding Sources}

There was no grant provided to write this paper.

\section{References}

1 Gahlot R, Nigam C, Kumar V, Yadav G, Anupurba S. Catheter-related bloodstream infections. Int J Crit Illn Inj Sci. 2014 Apr;4(2):162-7.

2 Raad I, Hanna H, Maki D. Intravascular catheter-related infections: advances in diagnosis, prevention, and management. Lancet Infect Dis. 2007 Oct;7(10):645-57.

3 National Nosocomial Infections Surveillance System. National Nosocomial Infections Surveillance (NNIS) System Report, data summary from January 1992 through June 2004, issued October 2004. Am J Infect Control. 2004 Dec;32(8):470-85.

4 Lee T, Barker J, Allon M. Tunneled catheters in hemodialysis patients: reasons and subsequent outcomes. Am J Kidney Dis. 2005 Sep;46(3):501-8. 


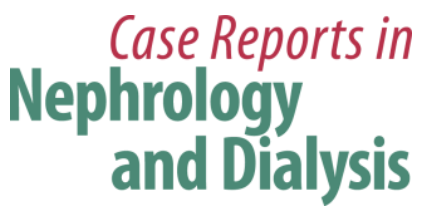

Case Rep Nephrol Dial 2018:8:121-129

DOI: $10.1159 / 000489923$

(C) 2018 The Author(s). Published by S. Karger AG, Base www.karger.com/cnd

El Nekidy et al.: Antibiotic Lock Solution in Hemodialysis Catheter Salvage

5 Graham J, Hiremath S, Magner PO, Knoll GA, Burns KD. Factors influencing the prevalence of central venous catheter use in a Canadian haemodialysis centre. Nephrol Dial Transplant. 2008 Nov;23(11):3585-91.

6 Vesely TM, Beathard G, Ash S, Hoggard J, Schon D; ASDIN Clinical Practice Committee. A position statement from the American Society of Diagnostic and Interventional Nephrology. Semin Dial. 2007 JulAug;20(4):359-64.

7 Hoggard J, Saad T, Schon D, Vesely TM, Royer T; American Society of Diagnostic and Interventional Nephrology, Clinical Practice Committee; Association for Vascular Access. Guidelines for venous access in patients with chronic kidney disease. A Position Statement from the American Society of Diagnostic and Interventional Nephrology, Clinical Practice Committee and the Association for Vascular Access. Semin Dial. 2008 Mar-Apr;21(2):186-91.

8 Agarwal AK. Central vein stenosis. Am J Kidney Dis. 2013 Jun;61(6):1001-15.

9 Trottier SJ, Veremakis C, O'Brien J, Auer AI. Femoral deep vein thrombosis associated with central venous catheterization: results from a prospective, randomized trial. Crit Care Med. 1995 Jan;23(1):52-9.

10 Schillinger F, Schillinger D, Montagnac R, Milcent T. Post catheterisation vein stenosis in haemodialysis: comparative angiographic study of 50 subclavian and 50 internal jugular accesses. Nephrol Dial Transplant. 1991;6(10):722-4.

11 Trerotola SO, Kuhn-Fulton J, Johnson MS, Shah H, Ambrosius WT, Kneebone PH. Tunneled infusion catheters: increased incidence of symptomatic venous thrombosis after subclavian versus internal jugular venous access. Radiology. 2000 0ct;217(1):89-93.

12 American Nephrology Nurses Association. https://www.annanurse.org/resources/special-projects-andtools/save-vein-campaign [accessed December 31, 2017].

13 Ontario Renal Network. http://www.renalnetwork.on.ca/hcpinfo/body_and_vascular_access/save_my_veins/\#.WaX4AmCWxMs [accessed December 31, 2017].

14 British Columbia Renal Agency. http://www.bcrenalagency.ca/resourcegallery/Documents/VeinPreservation-Renal-Patients-Update-Aug-17-2012.pdf [accessed December 31, 2017].

15 Mermel LA, Allon M, Bouza E, Craven DE, Flynn P, O'Grady NP, et al. Clinical practice guidelines for the diagnosis and management of intravascular catheter-related infection: 2009 Update by the Infectious Diseases Society of America. Clin Infect Dis. 2009 Jul;49(1):1-45.

16 Maya ID, Carlton D, Estrada E, Allon M. Treatment of dialysis catheter-related Staphylococcus aureus bacteremia with an antibiotic lock: a quality improvement report. Am J Kidney Dis. 2007 Aug;50(2):289-95.

17 Ashby DR, Power A, Singh S, Choi P, Taube DH, Duncan ND, et al. Bacteremia associated with tunneled hemodialysis catheters: outcome after attempted salvage. Clin J Am Soc Nephrol. 2009 Oct;4(10):1601-5.

18 Krishnasami Z, Carlton D, Bimbo L, Taylor ME, Balkovetz DF, Barker J, et al. Management of hemodialysis catheter-related bacteremia with an adjunctive antibiotic lock solution. Kidney Int. 2002 Mar;61(3): 1136-42.

19 Sofroniadou S, Revela I, Kouloubinis A, Makriniotou I, Zerbala S, Smirloglou D, et al. Ethanol combined with heparin as a locking solution for the prevention of catheter related blood stream infections in hemodialysis patients: A prospective randomized study. Hemodial Int. 2017 Oct;21(4):498-506.

20 Zapotoczna M, Murray EJ, Hogan S, O'Gara JP, Chhabra SR, Chan WC, et al. 5-Hydroxyethyl-3tetradecanoyltetramic acid represents a novel treatment for intravascular catheter infections due to Staphylococcus aureus. J Antimicrob Chemother. 2017 Mar;72(3):744-53.

21 Luiz MV, Scavone C, Tzanno C. The CLOCK trial, a double-blinded randomized controlled trial: trisodium citrate $30 \%$ and minocycline $3 \mathrm{mg} / \mathrm{mL}$ plus EDTA $30 \mathrm{mg} / \mathrm{mL}$ are effective and safe for catheter patency maintenance among CKD 5D patients on hemodialysis. Hemodial Int. 2017 Apr;21(2):294-304.

22 El Nekidy WS, El-Masri MM, Umstead GS, Dehoorne-Smith M. Predicting Maintenance Doses of Vancomycin for Hospitalized Patients Undergoing Hemodialysis. Can J Hosp Pharm. 2016 Sep-Oct;69(5):341-7.

23 Glanz S, Gordon DH, Lipkowitz GS, Butt KM, Hong J, Sclafani SJ. Axillary and subclavian vein stenosis: percutaneous angioplasty. Radiology. 1988 Aug;168(2):371-3.

24 Palabrica T, Lobb R, Furie BC, Aronovitz M, Benjamin C, Hsu YM, et al. Leukocyte accumulation promoting fibrin deposition is mediated in vivo by P-selectin on adherent platelets. Nature. 1992 Oct;359(6398): 848-51.

25 Weiss MF, Scivittaro V, Anderson JM. Oxidative stress and increased expression of growth factors in lesions of failed hemodialysis access. Am J Kidney Dis. 2001 May;37(5):970-80.

26 El Nekidy W, Dziamarski N, Soong D, Donaldson C, Ibrahim M, Kadri A. Cloxacillin-induced seizure in a hemodialysis patient. Hemodial Int. 2015 Oct;19(4):E33-6.

27 Raymond CB, Wazny LD, Sood AR. Standards of clinical practice for renal pharmacists. Can J Hosp Pharm. 2013 Nov;66(6):369-74. 


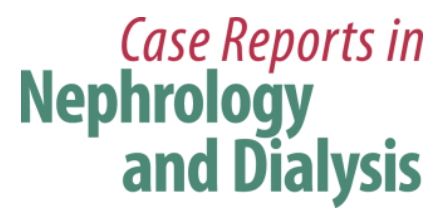

\begin{tabular}{l|l}
\hline Case Rep Nephrol Dial 2018;8:121-129 \\
\hline DOI: 10.1159/000489923 & $\begin{array}{l}\text { (c) } 2018 \text { The Author(s). Published by S. Karger AG, Basel } \\
\text { www.karger.com/cnd }\end{array}$ \\
\hline
\end{tabular}

28 Salgado TM, Moles R, Benrimoj SI, Fernandez-Llimos F. Pharmacists' interventions in the management of patients with chronic kidney disease: a systematic review. Nephrol Dial Transplant. 2012 Jan;27(1):276-92.

29 Vanholder R, Canaud B, Fluck R, Jadoul J, Labriola L, Marti-Monros A, et al. Diagnosis, prevention and treatment of haemodialysis catheter-related bloodstream infections (CRBSI): a position statement of European Renal Best Practice (ERBP). NDT Plus. 2010 Jun;3(10):234-46.

30 El Nekidy WS, El-Masri MM, Umstead GS, Dehoorne-Smith M. Factors influencing vancomycin loading dose for hospitalized hemodialysis patients: prospective observational cohort study. Can J Hosp Pharm. 2012 Nov;65(6):436-42.

Table 1. Composition of different lock solutions used for catheter salvage

\begin{tabular}{lcll}
\hline Drug & Concentration & Diluent & Anticoagulant concentration \\
\hline Cefazolin & $5 \mathrm{mg} / \mathrm{mL}$ & Normal saline & Heparin 5,000 units $/ \mathrm{mL}$ \\
Gentamicin & $5 \mathrm{mg} / \mathrm{mL}$ & Normal saline & N/A \\
Vancomycin & $2.5 \mathrm{mg} / \mathrm{mL}$ & Sterile water & $4 \%$ sodium citrate \\
\hline
\end{tabular}

The composition of antibiotic lock solutions was extracted from the literature and approved by the hospital pharmacy and therapeutics committee. Vancomycin/sodium citrate lock solution was chosen for practical aspects to avoid mixing polypeptide compounds. 